\title{
O uso da terra e sua influência sobre o volume das águas na Bacia do Rio Biguaçu/SC
}

Geovano Pedro Hoffmann** Arthur Schmidt Nanni ${ }^{* *}$

\section{Resumo}

Este estudo teve por objetivo identificar os condicionantes que promovem modificações no volume das águas na bacia hidrográfica do rio Biguaçu/SC em função das alterações no uso e cobertura da terra. A metodologia contemplou o levantamento de dados da precipitação, o mapeamento do uso e cobertura da terra dos anos de 1982 e 2014 e dos atuais canais fluviais retilinizados, bem como a estimativa do escoamento superficial para esta área de estudo sem registros hidrológicos contínuos. Os resultados obtidos demonstram que os condicionantes que promovem esta situação são socionaturais, indicando-se a variabilidade da precipitação associada à restrição da área florestal apenas no médio e alto curso, à ampliação das áreas descobertas e urbanizadas no baixo curso e à criação de trechos fluviais retilinizados. Ao final, são apresentadas recomendações frente ao futuro cenário de expansão da aglomeração urbana da Grande Florianópolis sobre o vale.

Palavras-chave: Uso e cobertura da terra; Vazões; Estimativa; Escoamento superficial.

Mestrando do PPGG - GCN-CFH/UFSC (hoffmange@hotmail.com).

** Professor do Depto. GCN-CFH/UFSC (arthur.nanni@ufsc.br).

Geosul, Florianópolis, v. 32, n. 63, p 97-116, jan./abr. 2017 
HOFFMANN, G.P. \& NANNI, A.S. O uso da terra e sua influência sobre...

Land use and its influence on the volume of water in the Biguaçu's/SC watershed

\begin{abstract}
This study aimed to identify the conditions that promote changes in the volume of water in the Biguaçu's/SC watershed in according with changes in use and land cover. The methodology has included the collection of rainfall data, the mapping of land use and cover to the years 1982 and 2014 and the current rectilineared river channels, as well as has estimated runoff for this study area without continuous hydrological records. The results show that the conditions that promote this are socionaturals indicating the variability of rainfall associated to the restriction of forest area only the middle and upper river course, the expansion of non-covered and urbanized areas in the lower course and the creation of river stretches rectilineared. Finally, recommendations are presented to the future expansion scenario of urban agglomeration of Florianópolis conurbation over the valley.

Key words: Use and land cover; Flow; Estimate; Runoff.
\end{abstract}

\title{
Introdução
}

Durante a evolução da paisagem em uma bacia hidrográfica, mecanismos naturais são criados para manter a quantidade e qualidade dos recursos hídricos presentes. Dentre estes, consta o vínculo entre o ciclo hidrológico e florestas, o qual tem o importante papel de regular a distribuição de energia e água a partir dos processos de interceptação, infiltração, escoamento e erosão (BALBINOT et al, 2008; LIMA, 2010).

Modificações deste vínculo, de floresta para qualquer outro tipo de uso e cobertura da terra, afetam direta ou indiretamente os processos hidrológicos. No que diz respeito ao escoamento, o impacto se reflete com a variação do comportamento fluvial, envolvendo problemas relacionados a enchentes, de vazão média e 
HOFFMANN, G.P. \& NANNI, A.S. O uso da terra e sua influência sobre...

do nível mínimo das águas, assim como alteração das condições ambientais locais (TUCCI, 2002).

Até o início do século XIX, a bacia hidrográfica do rio Biguaçu (BHB) era um ambiente em clímax que apresentava estabilidade entre os diferentes agentes que controlam sua dinâmica ambiental, tais como o clima, as formações geológicas, sua geomorfologia, a rede hidrográfica, os solos, a vegetação e a fauna. No entanto, a ocupação da BHB por imigrantes europeus, cujas técnicas de produção do espaço eram inadequadas ao manejo da terra para as suas condições geográficas, levou a uma situação vulnerável, visto que, com os elementos ambientais interligados num processo contínuo, houve a modificação especialmente dos processos hidrológicos como efeito compensatório. Neste contexto, o canal principal passou a dar indícios de assoreamento (REITZ, 1988), processo que se perpetua até os dias de hoje, sendo um indicativo de que o uso e cobertura da terra não estão ocorrendo de maneira apropriada na área (FORTES, 1996).

Reitz (1988) relata sobre a redução das águas da BHB, como percepção ambiental genérica da população que reside na área, afirmando que o canal principal apresentava águas mais profundas em épocas anteriores e que era utilizado no transporte hidroviário no vale, o que não é mais possível nos tempos atuais. Além do exposto, ocorre a situação inversa. De acordo com Santa Catarina (1997), a BHB possui uma frequência de mais de duas enchentes a cada cinco anos, o que a inclui na categoria de situação "grave" na classificação do Estado de Santa Catarina.

Este artigo tem por objetivo identificar os atuais condicionantes que promovem modificações no volume das águas na $\mathrm{BHB}$, uma vez que o conhecimento acerca do problema na área é escasso e a expansão da área de aglomeração urbana da Grande Florianópolis, tende a agravá-lo. 
HOFFMANN, G.P. \& NANNI, A.S. O uso da terra e sua influência sobre...

\section{Metodologia}

\section{Área de estudo}

A BHB (Figura 1) está localizada na porção central do litoral de Santa Catarina, estabelecida entre as coordenadas $27^{\circ} 22^{\prime}$ e 27 $34^{\prime}$ ' de latitude sul e $48^{\circ} 38^{\prime}$ e $48^{\circ} 56^{\prime}$ de longitude oeste. Possui uma área total de $389,7 \mathrm{~km}^{2}$ e drenagem disposta no sentido oesteleste, compreendendo todo o município de Antônio Carlos e parte do município de Biguaçu, ambos localizados na mesorregião da Grande Florianópolis. Apresenta a nascente do rio principal situada na Serra das Congonhas, a 778 metros de altitude, escoando numa extensão de 37 quilômetros até o município de Biguaçu, onde deságua no Oceano Atlântico (SILVA, 2007).

Figura 1 - Localização da bacia hidrográfica do rio Biguaçu/SC

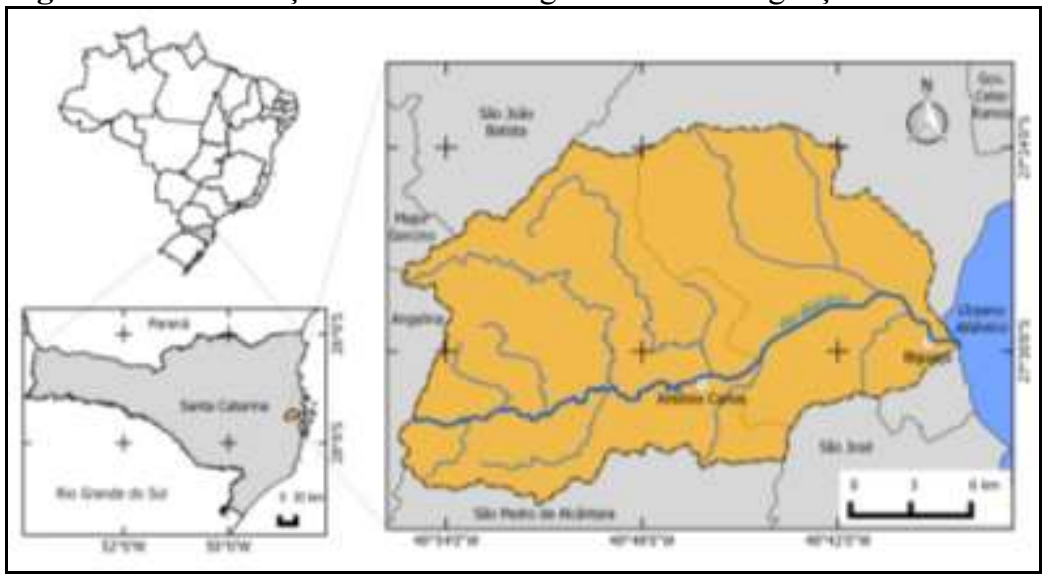

\section{Precipitação anual histórica}

Em virtude da precipitação ser um condicionante natural que apresenta rápidas modificações no decorrer do tempo, influindo diretamente sobre a variação do escoamento superficial, foi necessário englobar todo o período de registro de dados para a 
HOFFMANN, G.P. \& NANNI, A.S. O uso da terra e sua influência sobre...

BHB, desde 1911 até 2013, com a finalidade de traçar sua tendência e explicar como é a sua atuação na época atual. A série histórica de dados de precipitação também foi indispensável para o cruzamento com os relatos sobre a redução das águas, de Reitz (1988), e da frequência de enchentes, de Santa Catarina (1997), onde se buscou estabelecer relações entre as duas situações.

Os dados pluviométricos anuais utilizados para verificação desta variação da precipitação foram tomados como referência da estação mais próxima, de São José - SC (coordenadas 27²6'07'S e 48 37'11'O), mantida pela Empresa de Pesquisa Agropecuária e Extensão Rural de Santa Catarina (EPAGRI), em cooperação com o Centro Integrado de Informações Ambientais de Santa Catarina (CIRAM) e o Instituto Nacional de Meteorologia (INMET). São somente duvidosos os valores anuais referentes aos anos de 1930, 1959, 1961, 1963 e 1968 pela falta de dados em alguns meses de cada ano. Não há nenhum dado referente aos anos de 1920, 1921, 1939 e 1960.

\section{Representações cartográficas}

Para o mapeamento do uso e cobertura da terra foi realizado o comparativo de duas imagens de satélite, utilizando o sistema de informações geográficas QGIS. A primeira é referente à 9 de maio de 1982, da plataforma Landsat 3, ponto 79, órbita 236, obtida por meio do United States Geological Survey (USGS). Nela, foram reconhecidas as classes denominadas pelo IBGE (2013) de área urbanizada, cultura temporária, pastagem, campestre, florestal e vegetação em estágio sucessional. A imagem de satélite para o mapa do atual uso e cobertura da terra é proveniente da plataforma Landsat 8 , obtida também através do USGS. O registro é referente à 30 de janeiro de 2014, ponto 79, órbita 220. Nela foram identificadas as seguintes classes: área de mineração, área urbanizada, cultura permanente, cultura temporária, pastagem, silvicultura, campestre, florestal e área descoberta (com solo exposto). Vale ressaltar que a classe definida como "vegetação em estágio sucessional" estava incluída dentro da classificação do 
HOFFMANN, G.P. \& NANNI, A.S. O uso da terra e sua influência sobre...

IBGE (2013) denominada de "florestal", porém, optou-se por separá-la em virtude de sua abrangência na área de estudo.

Dentre os algoritmos da classificação supervisionada, o escolhido foi o da máxima verossimilhança (MaxVer), considerado um classificador eficiente. A interpretação da classificação de uso e cobertura da terra foi analisada da perspectiva altimétrica e geomorfológica, tomando como referência o curso principal, do rio Biguaçu, visto que corresponde a um padrão espacial de mudanças na região de estudo. As alterações do uso da terra foram compreendidas em baixo curso (do nível do mar até a cota de 35 metros, onde predominam depósitos aluvionares), médio curso (de 35 a 400 metros, o qual compreende a porção coluvionar) e alto curso (cota acima de 400 metros, onde predominam as zonas eluvionares).

No ambiente do QGIS, a partir do Modelo Numérico de Terreno (MNT) da Shuttle Radar Topography Mission (SRTM), foi possível a criação de uma camada temática hipsométrica. Os intervalos de altitude foram elaborados visando identificar as porções da BHB para a análise da dinâmica físico-temporal e demonstrar os desníveis topográficos da área de estudo.

Na porção do baixo curso, são registrados inúmeros trechos fluviais retilinizados. A identificação e intensidade destas retilinizações influencia diretamente o escoamento das águas, aumentando a velocidade de fluxo das mesmas. Estes trechos foram inicialmente mapeados por Fortes (1996), que identificou aqueles canais executados pelo extinto Departamento Nacional de Obras e Saneamento (DNOS). Os demais canais retilinizados foram identificados através de comparativo entre a rede hidrográfica atualizada com a das cartas topográficas vetorizadas da Mapoteca Digital de Santa Catarina (EPAGRI/CIRAM, 2014), cujas folhas são denominadas de Biguaçu (SG-22-Z D-II-4, do ano de 1974), Florianópolis (SG-22-Z D-V-2, do ano de 1981), Santo Amaro da Imperatriz (SG-22-Z D-V-1, do ano de 1974) e São João Batista (SG-22-Z D-II-3, do ano de 1974). Também corroborou para o mapeamento os locais onde havia a presença de meandros 
HOFFMANN, G.P. \& NANNI, A.S. O uso da terra e sua influência sobre... abandonados, possíveis de serem visualizados com as imagens de alta resolução do complemento online do QGIS, o OpenLayers/Google Satellite Layer, e indicações obtidas junto aos habitantes da região.

\section{Análise dos dados de estimativa do escoamento superficial}

Considerou-se que o escoamento apresenta como variáveis o tipo de cobertura da terra e a velocidade do fluxo de águas em superfície, ambas intimamente associadas. Em virtude da ausência de dados fluviométricos em série histórica para a área de estudo que possibilitassem a análise nesta pesquisa, foi realizado como método alternativo a estimativa do escoamento superficial médio para as porções de alto, médio e baixo curso da BHB. Assim, ressalva-se que o método trata-se de uma aproximação ao real valor e apresenta limitações. Para tal, foram utilizados os dados de Kibler (1982) apud Porto et al (2000), conforme a Tabela 1, obtidos a partir do resultado de diversas pesquisas experimentais, tanto de campo quanto de laboratório, e que refletem a velocidade média do escoamento em quatro tipos de superfícies, a saber, florestas, pastos, áreas cultivadas e pavimentos.

Tabela 1: Velocidades médias de escoamento superficial em $\mathrm{m} . \mathrm{s}^{-1}$

\begin{tabular}{ccccc}
\hline \multirow{2}{*}{ Cobertura } & \multicolumn{4}{c}{ Declividade (\%) } \\
\cline { 2 - 5 } & $\mathbf{0 - 3}$ & $\mathbf{4 - 7}$ & $\mathbf{8 - 1 1}$ & $>\mathbf{1 2}$ \\
\hline \multirow{2}{*}{ Florestas } & $0-$ & $0,5-$ & $0,8-$ & $>1,0$ \\
& 0,5 & 0,8 & 1,0 & \\
Pastos & $0-$ & $0,8-$ & $1,1-$ & \\
& 0,8 & 1,1 & 1,3 & $>1,3$ \\
Áreas & $0-$ & $0,9-$ & $1,4-$ & \\
cultivadas & 0,9 & 1,4 & 1,7 & $>1,7$ \\
\hline
\end{tabular}


HOFFMANN, G.P. \& NANNI, A.S. O uso da terra e sua influência sobre...

\begin{tabular}{ccccc}
\hline Pavimentos & $0-$ & $2,6-$ & $4,0-$ & \\
& 2,6 & 4,0 & 5,2 &
\end{tabular}

Fonte: Adaptado a partir de Kibler (1982) apud Porto et al (2000, p. 819).

O cálculo da velocidade média de escoamento superficial para cada porção da bacia hidrográfica considerou a técnica da ponderação, onde os dados da área de cada uso da terra foram multiplicados com os valores de velocidade média do escoamento superficial em bacia hidrográfica, conforme a declividade média de cada porção obtida com o software QGIS: $25,28 \%$ no alto curso, $7,83 \%$ no médio curso e $3,19 \%$ no baixo curso. Desta forma, cada valor utilizou como peso a área de abrangência das classes presentes na região. As classes de usos da terra do $\operatorname{IBGE}(2013$, p. 149) foram agrupadas com as de Kibler (1982) apud Porto et al (2000, p. 819), em conformidade com a semelhança de suas características físicas, principalmente infiltração e porte da vegetação, além do manejo do solo (Tabela 2).

Tabela 2: Relação entre as classes de uso e cobertura da terra da BHB entre IBGE (2013, p. 149) e Kibler (1982) apud Porto et al (2000, p. 819)

\begin{tabular}{ccc}
$\begin{array}{c}\text { Ano de } \\
\text { análise do } \\
\text { mapeamento }\end{array}$ & $\begin{array}{c}\text { Classes de uso e } \\
\text { cobertura da terra do } \\
\text { IBGE (2013, p. 149) }\end{array}$ & $\begin{array}{c}\text { Classes de uso e } \\
\text { cobertura da terra } \\
\text { segundo Kibler } \\
(\mathbf{1 9 8 2}) \text { apud } \text { Porto } \\
\text { et al (2000, p. 819) }\end{array}$ \\
\hline $\mathbf{1 9 8 2}$ & $\begin{array}{c}\text { Florestal; vegetação em } \\
\text { estágio sucessional }\end{array}$ & Florestas \\
& $\begin{array}{c}\text { Campestre, pastagem } \\
\text { Cultura temporária } \\
\end{array}$ & $\begin{array}{c}\text { Áreas cultivadas } \\
\text { Área urbanizada }\end{array}$ \\
\hline
\end{tabular}


HOFFMANN, G.P. \& NANNI, A.S. O uso da terra e sua influência sobre...

Florestal; silvicultura;

vegetação em estágio

sucessional

Campestre; pastagem

2014 Cultura permanente; cultura temporária

Florestas

rea descoberta; área de mineração, área

Pavimentos urbanizada

A partir do resultado da velocidade média de escoamento superficial para cada porção, houve ainda a necessidade da técnica de normalização a fim de se obter a contribuição de cada uso da terra em porcentagem para este escoamento. Assim, a soma do total da ponderação foi distribuída para cada classe de uso da terra de Kibler (1982) apud Porto et al (2000, p. 819), com valor resultante em 1 para se estabelecer a contribuição individual de cada classe em cada porção como um todo. A obtenção dos resultados sobre a influência do uso da terra sobre o escoamento em cada porção da BHB está sintetizada na equação (1).

$$
E S=\frac{\left[\frac{\text { florestas }}{A \times V m E S}+\frac{\text { pastos }}{A \times V m E S}+\frac{\text { areas cultivadas pavimentos }}{A \times V m E S}+\overparen{A \times V m E S}\right]}{\text { somatório de todas as áreas para todos os usos }(100 \%)}
$$

Onde: ES é o escoamento superficial médio de uma porção da $\mathrm{BHB}$, cujo valor máximo resultante é $1 ; A$ é a área $\mathrm{em}^{\mathrm{km}^{2}}$; e $V m E S$ é a velocidade média do escoamento superficial, adotada de acordo com a declividade média definida por Kibler (1982) apud Porto et al (2000, p. 819).

\section{Resultados e discussão}

\section{Condicionantes naturais}


HOFFMANN, G.P. \& NANNI, A.S. O uso da terra e sua influência sobre...

Analisando-se a série histórica de dados pluviométricos anuais para os anos de 1911 a 2013 (Figura 2), observa-se que, de um modo geral, grande parte dos valores anuais se manteve entre $1200 \mathrm{~mm}$ e $2000 \mathrm{~mm}$.

Figura 2: Precipitação anual para a série histórica 1911-2013 da estação São José - SC

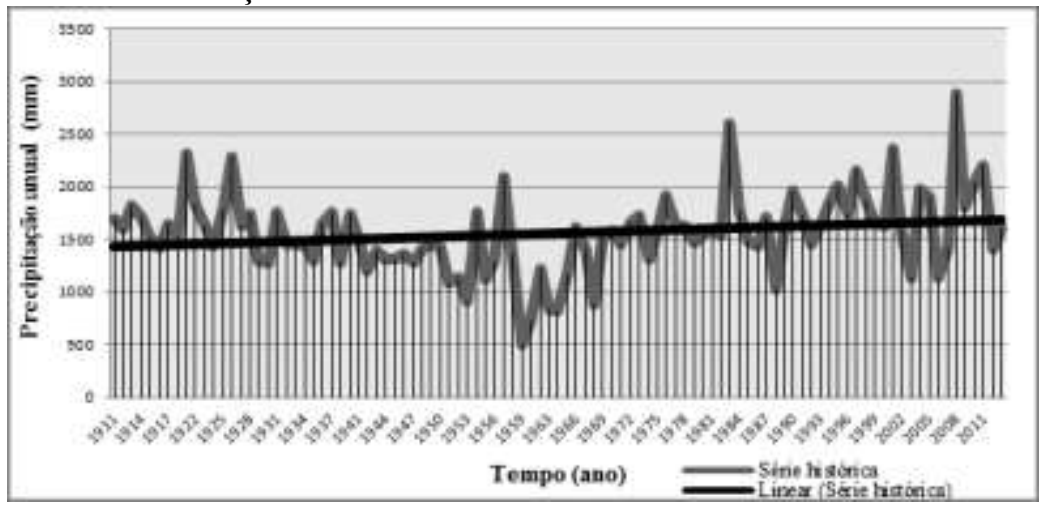

Fonte: EPAGRI/CIRAM/INMET (2014).

Em relação à média de precipitação anual da série $(1560,39$ $\mathrm{mm}$ ) observa-se que a precipitação aproxima-se dela até o final da década de 1920, havendo valores pontuais elevados. A partir de então ocorre um declínio que se encerra em meados da década de 1970, quando então o comportamento passa a ser o de aumento das médias até a atualidade.

De acordo com a tendência linear para todo o período, houve um acréscimo no volume das precipitações, porém há uma não linearidade no comportamento das mesmas, ocasionando acumulados de precipitação que se tornaram mais frequentes nas últimas décadas para a área de estudo. Assim, pela tendência de aumento de precipitações nas últimas décadas era esperado um aumento da quantidade das águas na $\mathrm{BHB}$, contudo este cenário não é sentido pela população, que compreende o contrário. 
HOFFMANN, G.P. \& NANNI, A.S. O uso da terra e sua influência sobre...

\section{Condicionantes antrópicos}

A partir dos resultados da classificação dos diferentes tipos de uso e cobertura da terra dos anos de 1982 e 2014 da bacia hidrográfica do rio Biguaçu, foi elaborada a Tabela 3, com as porcentagens que cada classe temática representa em relação à área total de cada porção (alto, médio e baixo curso) para cada período. A representação detalhada da classificação temática é encontrada na Figura 3.

Tabela 3: Área das classes de uso e cobertura da terra para cada porção da bacia hidrográfica do rio Biguaçu/SC em 1982 e 2014

\begin{tabular}{|c|c|c|c|c|c|c|c|c|c|c|c|c|}
\hline \multirow{3}{*}{$\begin{array}{c}\text { Uso e } \\
\text { cobertura } \\
\text { da terra }\end{array}$} & \multicolumn{4}{|c|}{ Alto Curso } & \multicolumn{4}{|c|}{ Médio Curso } & \multicolumn{4}{|c|}{ Baixo Curso } \\
\hline & \multicolumn{2}{|c|}{1982} & \multicolumn{2}{|c|}{2014} & \multicolumn{2}{|c|}{1982} & \multicolumn{2}{|c|}{2014} & \multicolumn{2}{|c|}{1982} & \multicolumn{2}{|c|}{2014} \\
\hline & $\mathrm{Km}^{2}$ & $\%$ & $\mathbf{K m}^{2}$ & $\%$ & $\mathbf{K m}^{2}$ & $\%$ & $\mathbf{K m}^{2}$ & $\%$ & $\mathbf{K m}^{2}$ & $\%$ & $\mathbf{K m}^{2}$ & $\%$ \\
\hline Florestas & 73 & 70 & 94 & 90 & 106 & 52 & 162 & 79 & 18 & 22 & 18 & 23 \\
\hline Pastos & 11 & 10 & 1 & 1 & 49 & 24 & 6 & 3 & 51 & 65 & 14 & 17 \\
\hline $\begin{array}{c}\text { Áreas } \\
\text { cultivadas }\end{array}$ & 21 & 20 & 8 & 8 & 48 & 24 & 32 & 15 & 7 & 9 & 33 & 42 \\
\hline Pavimentos & 0 & 0 & 0 & 0 & 1 & 0 & 6 & 3 & 4 & 4 & 14 & 18 \\
\hline Total & 105 & 100 & 103 & 100 & 204 & 100 & 206 & 100 & 80 & 100 & 79 & 100 \\
\hline
\end{tabular}


HOFFMANN, G.P. \& NANNI, A.S. O uso da terra e sua influência sobre...

Figura 3: Mapas do uso e cobertura da terra da bacia hidrográfica do rio Biguaçu/SC em 1982 e 2014

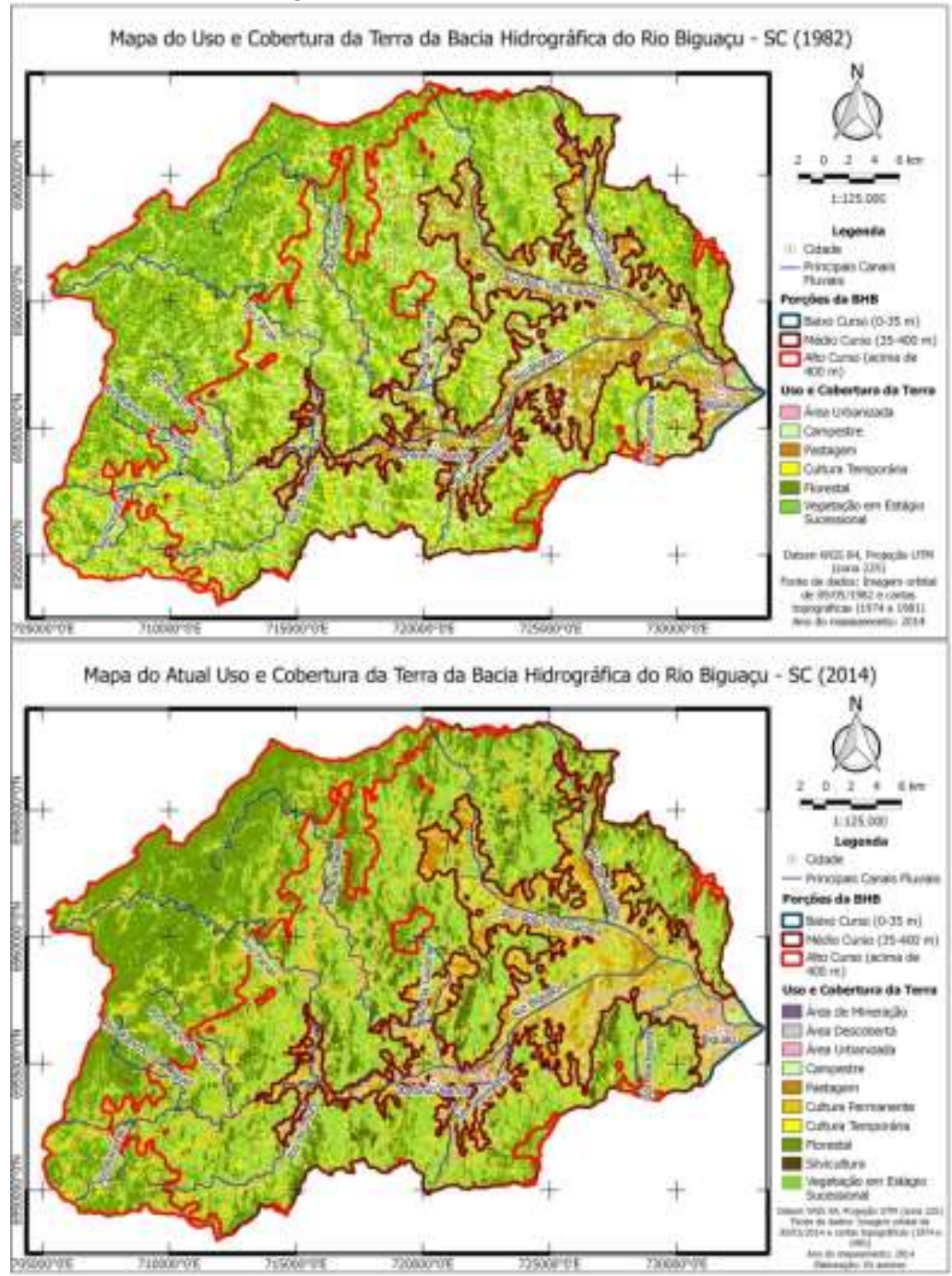


HOFFMANN, G.P. \& NANNI, A.S. O uso da terra e sua influência sobre...

No comparativo é possível notar que os usos e coberturas da terra sofreram transformações ao longo das últimas três décadas, com aumento ou redução de suas extensões. A influência destas mudanças sobre o volume das águas é demonstrada a seguir, representada pela Tabela 4 e Figura 4.

Tabela 4: Contribuição das classes de uso e cobertura da terra ao escoamento superficial médio para cada porção da bacia hidrográfica do rio Biguaçu/SC

\begin{tabular}{|c|c|c|c|c|c|c|c|c|c|}
\hline \multirow{2}{*}{$\begin{array}{c}\text { Uso e } \\
\text { cobertura da } \\
\text { terra }\end{array}$} & \multicolumn{3}{|c|}{ Alto curso } & \multicolumn{3}{|c|}{ Médio curso } & \multicolumn{3}{|c|}{ Baixo curso } \\
\hline & $\begin{array}{c}\mathrm{V} . \\
\text { média } \\
\left(\mathbf{m} / \mathbf{s}-^{1}\right)\end{array}$ & 1982 & 2014 & $\begin{array}{c}\mathrm{V} . \\
\text { média } \\
\left(\mathrm{m} / \mathrm{s}^{1}\right)\end{array}$ & 1982 & 2014 & $\begin{array}{c}\mathrm{V} . \\
\text { média } \\
\left(\mathrm{m} / \mathbf{s}^{-1}\right)\end{array}$ & 1982 & 2014 \\
\hline Florestas & 2,1 & 0,59 & 0,84 & 0,8 & 0,4 & 0,64 & 0,5 & 0,12 & 0,1 \\
\hline Pastos & 2,7 & 0,11 & 0,02 & 1,1 & 0,26 & 0,03 & 0,9 & 0,65 & 0,13 \\
\hline $\begin{array}{c}\text { Áreas } \\
\text { cultivadas }\end{array}$ & 3,6 & 0,29 & 0,13 & 1,4 & 0,32 & 0,22 & 1 & 0,09 & 0,35 \\
\hline Pavimentos & 11 & 0,01 & 0,02 & 4 & 0,02 & 0,11 & 2,8 & 0,14 & 0,42 \\
\hline
\end{tabular}

Os gráficos da Figura 4 são referentes às tendências lineares do escoamento superficial médio para cada porção da BHB para os anos de 1982 e 2014. 
HOFFMANN, G.P. \& NANNI, A.S. O uso da terra e sua influência sobre...

Figura 4: Tendências lineares de 1982 e 2014 da contribuição de cada classe de uso e cobertura da terra ao escoamento superficial médio para cada porção da bacia hidrográfica do rio Biguaçu/SC

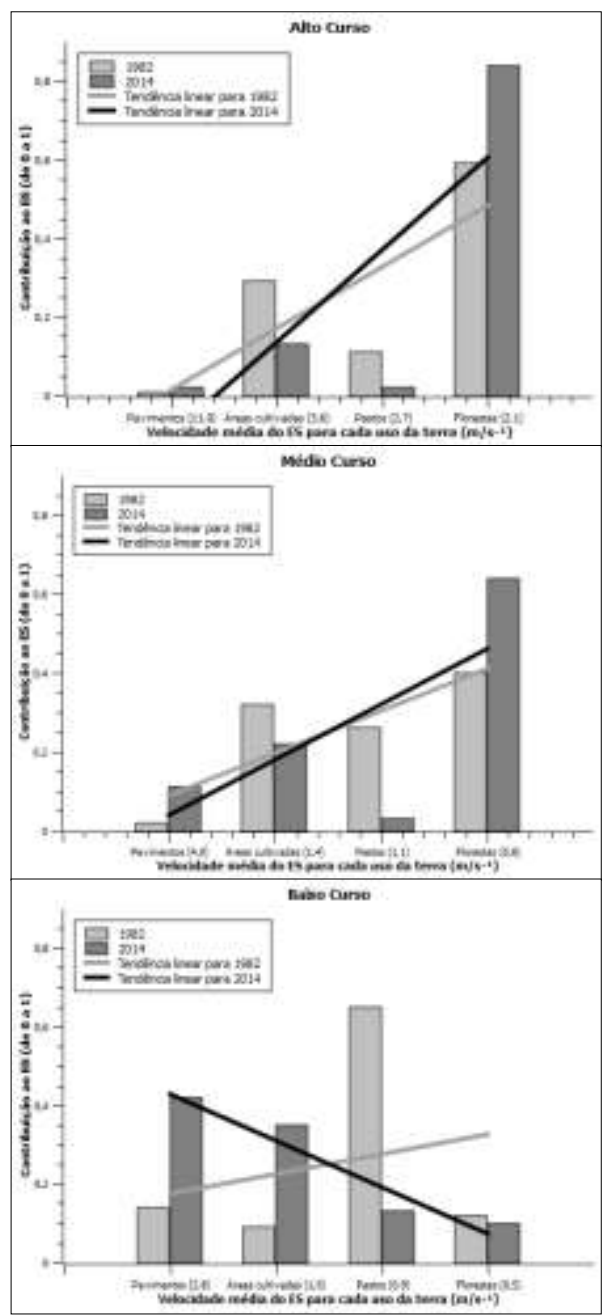


HOFFMANN, G.P. \& NANNI, A.S. O uso da terra e sua influência sobre...

Alto curso

Percebe-se que a contribuição de florestas ao escoamento superficial foi expandida consideravelmente no alto curso para 0,84 e é um excelente indicativo, visto que possibilita um regime contínuo dos cursos d'água de cabeceira que suprem os cursos fluviais de maior expressão na bacia hidrográfica, especialmente em períodos de estiagem. A atual cobertura em sua grande parte por florestas permite melhor infiltração da precipitação nos solos, favorecendo o escoamento subsuperficial e subterrâneo, mantendo assim o nível de base. Devido à sua baixa velocidade média de fluxo, de $2,1 \mathrm{~m} / \mathrm{s}^{-1}$, retarda a ação dos processos erosivos que provocam movimentos de massa, assim como o assoreamento do baixo curso. Como demonstrado pelas linhas de tendência linear da Figura 4 para o alto curso, os usos de menor velocidade média de escoamento superficial se sobrepuseram aos de maior velocidade durante os dois períodos avaliados.

\section{Médio curso}

As linhas de tendência do médio curso mostram que os usos da terra de menor velocidade média de escoamento se mantêm sobre os usos com maior velocidade no comparativo entre os dois períodos (Figura 4). Assim, no que diz respeito aos efeitos sobre o escoamento superficial, houve aumento da contribuição das classes de florestas $(0,64)$ e de pavimentos $(0,11)$ e redução por parte das classes de áreas cultivadas $(0,22)$ e pastos $(0,03)$. Esta condição é semelhante ao que ocorreu no alto curso, porém, devido a menor área de florestas em comparação entre estas porções, infere-se que nesta há uma maior contribuição dos usos da terra de maiores velocidades médias aos fluxos de água em superfície.

\section{Baixo curso}

De maneira inversa ao alto e médio curso, as velocidades de escoamento superficial de 1982 se inverteram para a condição de 2014. Na condição atual, há maior contribuição ao escoamento superficial global do baixo curso, provocada principalmente pelo 
HOFFMANN, G.P. \& NANNI, A.S. O uso da terra e sua influência sobre...

crescimento da área de pavimentos $(0,49)$ e de áreas cultivadas $(0,35)$ em detrimento das classes de pastos $(0,13)$ e florestas $(0,1)$.

O baixo curso apresenta uma ocupação do uso da terra inadequada e conflituosa, uma vez que as classes de cobertura que mais contribuem são aquelas que detêm a maior velocidade média de escoamento, como evidenciado nas linhas de tendência linear, dificultando os processos de infiltração e evapotranspiração. Com o aumento do fluxo em superfície, há o encurtamento do tempo de concentração das águas e a antecipação do tempo de pico da vazão máxima, gerando maior frequência de enchentes e inundações, como registrada em Santa Catarina (1997), além de favorecer o aceleramento dos processos erosivos. Em contrapartida, o baixo curso é o que menos contribui ao escoamento de base para o fornecimento de água à calha principal da bacia hidrográfica, em consequência da limitada área de florestas, explicando em parte o baixo nível mínimo das águas registrado em Reitz (1988).

Associados a este arranjo espacial, os trechos fluviais retilinizados do baixo curso continuam sendo importantes como fator de modificação do uso da terra na bacia hidrográfica do rio Biguaçu e do seu escoamento. De acordo com Cunha (2012), a retilinização refere-se à remodelagem dos canais fluviais, de maneira a torná-los retilíneos por meio da eliminação de meandros e da diminuição da extensão dos cursos d'água por grandes distâncias. A altura do nível das cheias é forçada a diminuir através do aumento do declive do leito, acelerando a velocidade do fluxo das águas e, por consequência, o escoamento na bacia hidrográfica.

Segundo Fortes (1996), os canais sinuosos dos rios que drenam o baixo vale do rio Biguaçu foram profundamente alterados pelas obras de engenharia hidráulica realizadas pelo extinto DNOS (Figura 5). Entre 1966 e 1970, o rio Biguaçu foi retilinizado numa extensão de cerca de $10,7 \mathrm{~km}$. Também houve a retilinização dos afluentes do rio principal, dentre eles, os rios da Saudade, dos Três Riachos, Rachadel, da Guiomar e do Ribeirão Vermelho. As obras recentes dos últimos anos se concretizam ou 
HOFFMANN, G.P. \& NANNI, A.S. O uso da terra e sua influência sobre... pela ação do Estado na esfera municipal ou por iniciativa própria de particulares para outro aproveitamento das terras.

Figura 5: Mapa dos canais fluviais retilinizados da bacia hidrográfica do rio Biguaçu/SC em 2014

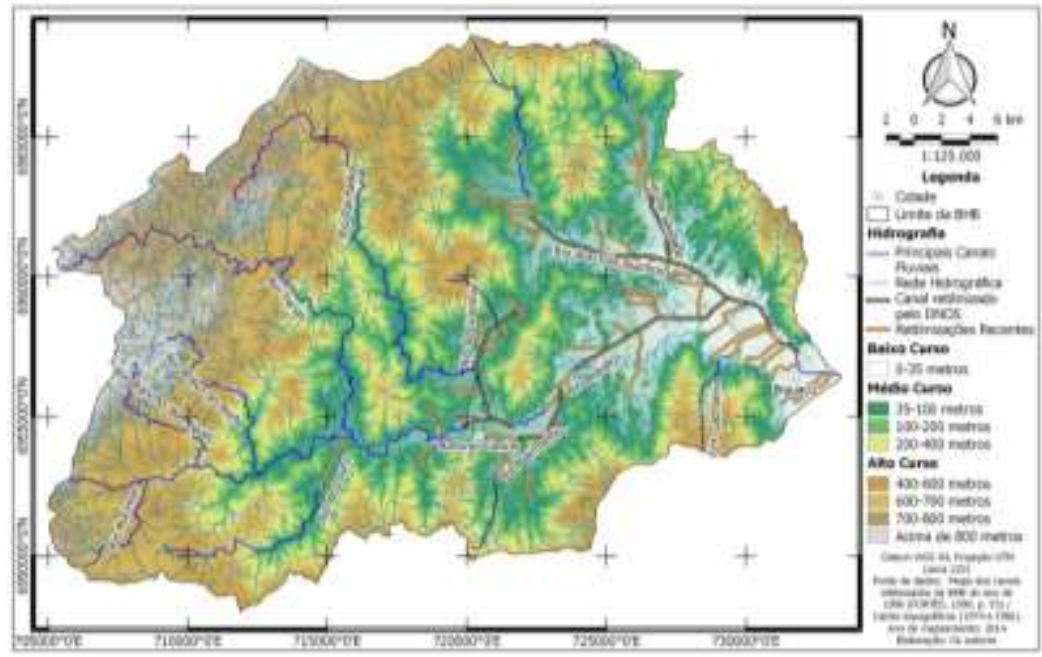

Cunha (2012) destaca que após alguns anos das obras de retilinização, há o ajustamento da morfologia do canal; em algumas dezenas, o padrão de drenagem é ajustado e, somente depois de algumas centenas de anos é que há o novo equilíbrio com a rede de drenagem adaptada. Tais observações retratam o caráter ineficaz destas obras em diminuir os problemas relacionados às inundações e, acima de tudo, intensificam a ocupação das margens dos rios e planícies de inundação, ampliando a área de impermeabilização.

De maneira geral, antes da substituição da cobertura vegetal por outros usos da terra, os efeitos sobre as vazões dos sistemas hídricos da BHB ocorriam com picos de cheias de escoamento mais lento, porém, de pequena magnitude, afetando uma área menor da planície de inundação e mantendo um nível mínimo de vazão média, com razoável volume que ainda possibilitava o uso das águas para navegação fluvial 
HOFFMANN, G.P. \& NANNI, A.S. O uso da terra e sua influência sobre...

na bacia hidrográfica. Contudo, conforme Schueler (1987) apud Tucci (2002), durante e após o processo de urbanização, a maior parte da chuva efetiva transforma-se em escoamento superficial concentrado, que articulado aos trechos fluviais retilinizados, tem como consequência o aumento abrupto do volume das águas, com picos de cheias maiores e mais rápidos, num pequeno período de concentração e de retardo, o que amplia a área da planície de inundação e torna as enchentes de aspecto mais intenso. Por outro lado, há a redução da vazão média e do nível mínimo do escoamento de base no período que se sucede.

\section{Considerações finais}

A irregularidade do volume das águas frente ao uso da terra representa uma série de consequências à BHB. As inundações trazem prejuízos que ocorrem na forma de perdas materiais e risco às vidas, bem como perdas de produção nas atividades agropastoris e de indústria, haja vista que estão instalados na área de planície que é naturalmente o espaço pertencente aos rios. A redução das vazões mínimas leva a problemas vinculados à irrigação, à qualidade das águas (já que depende da autodepuração nos cursos fluviais), aos poços de água para abastecimento domiciliar, à biota presente que depende dela para sobreviver, dentre outros.

Mesmo com o aumento da precipitação desde a década de 1980, a percepção da população residente, que se concentra na porção do baixo rio Biguaçu, é de que não houve a retenção hídrica na bacia hidrográfica. Isso leva a crer que há a concentração do escoamento superficial no tempo, com aumento das vazões em curtos períodos e a redução das mesmas durante médios e longos períodos. Os condicionantes que promovem esta situação são socionaturais, indicando-se a variabilidade da precipitação ao longo do tempo, a ampliação das áreas de pavimentos, principalmente no baixo curso, que impedem a infiltração e favorecem o escoamento superficial; a presença de trechos fluviais retilinizados, que fazem com que as águas escoem mais rapidamente; e a restrição da área florestal apenas no médio e alto 
HOFFMANN, G.P. \& NANNI, A.S. O uso da terra e sua influência sobre...

curso da $\mathrm{BHB}$, o que promove o suprimento dos principais mananciais de origem subsuperficial, porém, no baixo curso continua reduzida em função das áreas de cultivos, pastos e pavimentos, os quais intensificam o fluxo de águas em superfície.

Como a contribuição dos usos da terra ao escoamento superficial no baixo curso aumentou em relação à década de 1980, a tendência, a médio e longo prazo, é que se acentue devido ao fenômeno da urbanização. Associados à expansão da aglomeração urbana na mesorregião, com o andamento da construção de grandes empreendimentos imobiliários, loteamentos, áreas industriais e do contorno viário da Grande Florianópolis, é possível inferir que este conjunto de fatores, no cenário futuro, promoverá a interiorização da mancha urbana conurbada no vale. Deste modo, as áreas de florestas poderão ser novamente substituídas pelas áreas de cultivo e de pastos no médio e alto curso, já que o baixo curso dará lugar, logicamente através da valorização imobiliária, à áreas pavimentadas. Estas novas e mais complexas modificações de uso e cobertura da terra na BHB agravarão o problema do comportamento irregular do escoamento e refletirão em inundações cada vez mais rápidas e de maior impacto, uma vez que o crescimento demográfico da região estará maior sobre as áreas inundáveis da planície que foram drenadas, assim como redução ainda maior do nível mínimo das águas, levando a conflitos de uso mais dramáticos.

Portanto, torna-se de suma importância a implementação de um plano em nível de bacia hidrográfica que realize o planejamento e a orientação da ocupação territorial no baixo curso da BHB, onde estão concentrados atualmente os problemas relacionados à quantidade das águas, bem como a conservação das áreas florestais do médio e alto curso. Como resultado do processo histórico que iniciou com a colonização da região, segue ainda insistentemente como paradigma de boas práticas de gestão territorial.

As atuais políticas públicas precisam ser revistas para que a expansão das áreas de pavimentos não superem a capacidade comportada pelas condições ambientais da bacia hidrográfica. Da mesma forma, é também relevante que haja o monitoramento e a 
HOFFMANN, G.P. \& NANNI, A.S. O uso da terra e sua influência sobre...

recuperação do ambiente fluvial anterior às obras de retilinização no intuito de amenizar os efeitos hidrológicos negativos e compensatórios que já ocorrem, permitindo que o próprio canal siga livremente à sua evolução morfológica meandrante, e que esteja agregada à primeira recomendação.

Uma limitação para o propósito deste estudo foi a inexistência de registros contínuos do nível das águas na área de estudo que servissem de incremento à pesquisa. A BHB é uma das poucas unidades hidrográficas de Santa Catarina que ainda não possui estação fluviométrica, sendo que o próprio Estado a enquadrou em situação grave na classificação de enchentes. Em virtude das necessidades recorrentes para o monitoramento e para posteriores estudos sobre a região no que tange ao escoamento, aconselha-se a instalação desta para ser incorporada à rede atual do estado e do país.

\section{Referências bibliográficas}

BALBINOT, R.; OLIVEIRA, N. K.; VANZETTO, S. C.; PEDROSO, K.; VALERIO, A. F. O papel da floresta no ciclo hidrológico em bacias hidrográficas. In: Ambiência. Guarapuava, v. 4, n. 1, p. 131-149, jan./abr., 2008.

CUNHA, S. B. Rios desnaturalizados. In: BARBOSA, J. L. (Org.). Ordenamento Territorial e Ambiental. 1. ed. Niterói: EDUFF, 2012, p. 171-191.

EPAGRI - Empresa de Pesquisa Agropecuária e Extensão Rural de Santa Catarina/ CIRAM - Centro Integrado de Informações Ambientais de Santa Catarina. Mapas Digitais de Santa Catarina: Mapoteca Topográfica Digital de Santa Catarina. cooperação técnica IBGE/EPAGRI. Disponível em: $<$ http://ciram.epagri.sc.gov.br/mapoteca/>. Acesso em: 25.jan.2014.

FORTES, E. A planície costeira da região de Biguaçu - SC: abordagens dos aspectos ambientais da bacia hidrográfica do Rio 
HOFFMANN, G.P. \& NANNI, A.S. O uso da terra e sua influência sobre...

Biguaçu. Florianópolis, 1996. 216 p. Dissertação (Mestrado) Centro de Filosofia e Ciências Humanas, Universidade Federal de Santa Catarina.

LIMA, W. P. A silvicultura e a água: ciência, dogmas, desafios. Rio de Janeiro: Instituto Bioatlântica, 2010. 64 p.

IBGE - INSTITUTO BRASILEIRO DE GEOGRAFIA E ESTATÍSTICA. Manual técnico de uso da terra. 3. ed. Rio de Janeiro: IBGE, 2013. 171 p.

PORTO, R.; ZAHEL, F. K.; TUCCI, C. E. M.; BIDONE, F. Drenagem urbana. In: TUCCI, C. E. M (Org.). Hidrologia: ciência e aplicação. 2. ed. Porto Alegre. Ed. UFRGS/ABRH, 2000, p. 805847.

REITZ, R. Alto Biguaçu: narrativa cultural tetrarracial. Florianópolis: Ed. Lunardelli/Ed. da UFSC, 1988. 584p.

SANTA CATARINA. Secretaria do Desenvolvimento Urbano e do Meio Ambiente. Bacias hidrográficas de Santa Catarina: diagnóstico geral. Florianópolis, 1997. 163 p.

SILVA, Vicente Rocha. Análise sócio-ambiental da Bacia do Rio Biguaçu - SC: subsídios ao planejamento e ordenamento territorial. Tese (Doutorado). São Paulo, 2007. 209 p. Faculdade de Filosofia, Letras e Ciências Humanas, Universidade de São Paulo.

TUCCI, C. E. M. Impactos da variabilidade climática e uso do solo sobre os recursos hídricos. In: FÓRUM BRASILEIRO DE MUDANÇAS CLIMÁTICAS, ANA, 2002. 150 p.

Recebido em abril de 2015

Aceito em maio de 2016 